\title{
Analysis of CYP2D6 Allele Frequencies and Identification of Novel SNPs and Sequence Variations in Sardinians
}

\author{
Matteo Falzoi, ${ }^{1,2,3}$ Luigi Pira, ${ }^{1}$ Paolo Lazzari, ${ }^{1}$ and Luca Pani ${ }^{2}$ \\ ${ }^{1}$ PharmaNess S.c.a r.l., Parco Scientifico e Tecnologico della Sardegna, Ed. 5, Loc. Piscinamanna, 09010 Pula, Italy \\ ${ }^{2}$ Unità Operativa di Cagliari, Istituto di Farmacologia Traslazionale del Consiglio Nazionale delle Ricerche CNR-IFT, \\ Parco Scientifico e Tecnologico della Sardegna, Ed. 5, Loc. Piscinamanna, 09010 Pula, Italy \\ ${ }^{3}$ Dipartimento di Scienze della Vita e dell'Ambiente, Università degli Studi di Cagliari, Laboratori di Genetica, \\ Via T. Fiorelli 1, 09126 Cagliari, Italy
}

Correspondence should be addressed to Luigi Pira; luigi.pira@pharmaness.com

Received 5 July 2012; Accepted 22 August 2012

Academic Editors: M. A. Chiurillo, G. Giovambattista, and K. Omi

Copyright (C) 2013 Matteo Falzoi et al. This is an open access article distributed under the Creative Commons Attribution License, which permits unrestricted use, distribution, and reproduction in any medium, provided the original work is properly cited.

\begin{abstract}
The CYP2D6 enzyme is involved in the metabolism of many commonly prescribed drugs. The presence of polymorphisms in the CYP2D6 gene may modulate the enzyme level and activity affecting individual responses, to pharmacological treatment in drug level, response and adverse reactions. Aims. This study aimed to analyze the determination of allele frequencies in Sardinians and the comparison to frequencies found in the Caucasian Population. Methods and Materials. We used a Long PCR strategy coupled to direct genomic DNA sequencing analysis. An amplification allele-specific was carried out to infer the correct allelic phase. The TaqMan Gene Copy Number Assay (Applied Biosystems) was used to verify the presence of gene deletions/multiplications. Results and Conclusions. Our results indicated that CYP2D6 allele frequencies in Sardinians differed from those previously detected in the Caucasian Population. Moreover, three new SNPs and four novel haplotypes were identified.
\end{abstract}

\section{Introduction}

Cytochrome P450 2D6 (CYP2D6) is a highly polymorphic gene, which is responsible for the metabolism of several key endogenous substrates and other xenobiotics [1] and about $25 \%$ of the most commonly prescribed drugs [2-4] (Table 1). More than 130 Single Nucleotide Polymorphisms (SNPs) have been identified within the CYP2D6 gene, including numerous nonsynonymous variations, as well as silent, promoter, and intronic changes. The 82 allelic variants and numerous subvariants reported to date are summarized in the Human CYP Allele Nomenclature Committee website [5]. The presence of SNPs can alter CYP2D6 enzymatic activity with effects ranging considerably within a population and includes individuals with ultrarapid (UM), extensive (EM), intermediate (IM), and poor (PM) metabolizer status. Furthermore, rearrangements within the gene locus have created multiple functional gene copies or deleted the entire gene, resulting in increased or absent drug metabolism, respectively $[6,7]$. Genotypic analysis to identify individual polymorphisms has become increasingly important during drug development and for selection of individualized therapies. This analysis aims to increase the number of responders and to limit the incidences of adverse events.

In our previous work [8], we tried to create a complete genotyping method for the simultaneous analysis of CYP3A4, CYP3A5, CYP2C9, CYP2C19, and CYP2D6 SNPs. The genotyping of the CYP2D6 gene was difficult due to its polymorphic nature, the presence of two flanking pseudogenes, and copy number variants. To avoid false genotyping, resulting from nonspecific coamplification of the highly homologous pseudogenes, the analysis of this gene was not included in our previous study.

For this reason, we aimed to create a primary CYP2D6 PCR strategy based on the amplification of the entire gene $(6.572 \mathrm{~Kb})$ coupled to direct genomic DNA sequencing analysis. This strategy avoids false genotyping, which would result in nonspecific coamplification of the homologous pseudogenes. 
TABLE 1: Class list of major CYP2D6 isoenzyme substrates [3, 4].

CYP2D6 isoenzyme major substrates

Tricyclic antidepressants

Tetracyclic antidepressants

Selective serotonin reuptake inhibitors

Serotonin-norepinephrine reuptake inhibitors

Opioids

Antipsychotics

Selective estrogen receptor modulator

$\beta$-blockers

Antihypertensives

Antiarrhythmics

Antitussives

Antiemetics

Antidiabetics

Histamine antagonists

Dopamine antagonists

Antimitotics

The choice of the population to be studied may be critical. Isolated populations, such as that found in Sardinia $[9,10]$, could be extremely useful for mapping novel SNPs and haplotypes for specific genes. There are very few studies on CYP450 subfamily genes in Sardinian people $[8,11$, 12]; therefore, we analyzed the CYP2D6 gene for sequence variations in Sardinians and also compared resulting allele frequencies with those observed in Caucasian population.

\section{Methods and Materials}

2.1. DNA Samples. Genomic DNA extracted from blood samples of 250 healthy Sardinian individuals were furnished by Professor Francesco Cucca, INN-CNR Cagliari Director. All participating individuals provided informed consent to genetic test.

2.2. Long Primary PCR. Selective amplification of the CYP2D6 gene was carried out using a Long PCR protocol. In particular, a forward primer ( $\mathrm{P}-1780$, Table 2$)$, was designed in a highly nonhomologous CYP2D6/CYP2D7P/CYP2D8P 5 ' untranslated region (nucleotides -1780_-1758 according to the AY545216 sequence [13]). The reverse primer used was 2D6-R (Table 2), as previously described [14]. A $5^{\prime}$ 10-mer tag (5'-ACGTTGGATG-3') was added to both PCR primers in order to improve PCR efficiency. PCR reactions were performed in a final volume of $50 \mu \mathrm{L}$ using the QIAGEN (Hilden, Germany) LongRange PCR Kit protocol [15] with the following minor modifications: $100 \mathrm{ng}$ genomic DNA, $500 \mu \mathrm{M}$ of each PCR Primer (Metabion, Martinsried, Germany), 1 U QIAGEN LongRange PCR Enzyme, 1X QIAGEN LongRange PCR Buffer (containing $\mathrm{MgCl}_{2} 25 \mathrm{mM}$ ) and $800 \mu \mathrm{M}$ Invitrogen (CA, USA) 2'-deoxynucleoside-5' triphosphate (dNTP) Set PCR Grade. The PCR conditions were as follows: initial denaturation at $93^{\circ} \mathrm{C}$ for $3 \mathrm{~min} ; 40$ cycles at $93^{\circ} \mathrm{C}$ for $30 \mathrm{~s}, 61^{\circ} \mathrm{C}$ for $30 \mathrm{~s}$, and $68^{\circ} \mathrm{C}$ for $6 \mathrm{~min}$.
2.3. CYP2D6 Sequencing Analysis. For sequencing reactions, we used primers designed by both the Assay Designer Suite [16] and Primer3 v.0.4.0 [17], and some others found in the public literature $[14,18]$ (Table 3). Forward and reverse primers were used to sequence both strands of the whole gene. The generated CYP2D6 $6.572 \mathrm{~Kb}$ gene amplicon was submitted to inactivation of unincorporated dNTPs by adding $20 \mu \mathrm{L}$ of ExoSAP-IT (USB, OH, USA) to each $50 \mu \mathrm{L}$ aliquot of PCR product. Purification conditions were as follows: $37^{\circ} \mathrm{C}$ for $60 \mathrm{~min}$ and $85^{\circ} \mathrm{C}$ for $15 \mathrm{~min}$. To each $2.5 \mu \mathrm{L}$ aliquot of PCR/Purification, $7 \mu \mathrm{M}$ of each PCR Sequencing Primer (Metabion), 1X BigDye Terminator v3.1 Ready Reaction mix (Applied Biosystems), 1.5X BigDye Terminator (Applied Biosystems) and sterilized $\mathrm{H}_{2} \mathrm{O}_{d d}$ were added to reach a final volume of $10 \mu \mathrm{L}$. Thermal cycler conditions were as follows: 25 cycles at $95^{\circ} \mathrm{C}$ for $30 \mathrm{~s}, 50^{\circ} \mathrm{C}$ for $15 \mathrm{~s}$, and $60^{\circ} \mathrm{C}$ for $4 \mathrm{~min}$. For primers CYP2D6_01_F, 1863_1864insTTTCGCCCC and 2291G>A, the annealing conditions were modified as follows: 25 cycles at $95^{\circ} \mathrm{C}$ for $30 \mathrm{~s}, 60^{\circ} \mathrm{C}$ for $15 \mathrm{~s}, 60^{\circ} \mathrm{C}$ for $4 \mathrm{~min}$. For primers $\mathrm{P}-1780$ and 2D6-R [14], an initial denaturation was added as follows: initial denaturation at $95^{\circ} \mathrm{C}$ for $3 \mathrm{~min} ; 25$ cycles at $95^{\circ} \mathrm{C}$ for 30 $\mathrm{s}, 50^{\circ} \mathrm{C}$ for $15 \mathrm{~s}$, and $60^{\circ} \mathrm{C}$ for $4 \mathrm{~min}$. All amplified products were cleaned with EDTA $125 \mathrm{mM}$ and ethanol, resuspended in $12 \mu \mathrm{L}$ formamide and, before sequencing analysis, submitted to denaturation at $92^{\circ} \mathrm{C}$ for $2 \mathrm{~min}$. DNA sequencing reactions were carried out using a 3730 48-Capillary DNA Analyzer (Applied Biosystems) and MicroAmp Optical 96 Well Plates (Applied Biosystems). Sequences deposited in GenBank (M33388 [19], AY545216 [13]) served as reference for CYP2D6.

2.4. Copy Number Variation (CNV) Analysis. The presence of CYP2D6 gene deletion (CYP2D6 ${ }^{*} 5$ allele) and duplications/multiplications was evaluated in all 250 Sardinian DNA samples using CYP2D6 TaqMan Gene Copy Number Assay (Applied Biosystems) [20]. Reactions were performed in a final volume of $10 \mu \mathrm{L}$ containing $10 \mathrm{ng}$ of genomic DNA, 2X TaqMan Universal PCR Master Mix, 1X TaqMan VICRNase P Assay, and 1X TaqMan FAM-labelled CYP2D6 gene specific assay Hs00010001_cn. Thermal cycler conditions were as follows: $95^{\circ} \mathrm{C}$ for $10 \mathrm{~min}$ followed by 40 cycles of $95^{\circ} \mathrm{C}$ for $15 \mathrm{~s}$ and $60^{\circ} \mathrm{C}$ for $60 \mathrm{~s}$. Gene deletion or duplications/multiplications presence was evaluated using analysis software furnished with the TaqMan CNV Assay.

2.5. Haplotype Determination/Identification. We used the Maximum-Likelihood Estimation (MLE), based on the Expectation-Maximization (EM) algorithm [21, 22] to infer haplotype combinations from genotype information. MLE is a statistical tool used for fitting a statistical model to data and providing estimates for the model's parameters. This method corresponds to many well-known estimation methods in statistics, particularly when cost or time are constraining. MLE assumes that data have a Gaussian distribution with an unknown mean and variance. The mean and variance can be estimated with MLE while only knowing the data of a sample from the overall samples. MLE accomplishes 
TABLE 2: List of primers used in CYP2D6 Long PCR protocols. P-1780 was designed in a highly non-homologous CYP2D6/ CYP2D7P/CYP2D8P 5' untranslated region (nucleotides -1780_-1758 according to AY545216 sequence [13]). P-1584_WT and P-1584_MUT are modification of primer -1584G>C (Table 3) by addiction of a $3^{\prime}$-dNTP complementary to wild-type (WT) nucleotide or SNP (MUT), to create an amplification allele-specific. The 5 ' 10 -mer tag was added to PCR primers, in order to improve PCR efficiency.

\begin{tabular}{lllll}
\hline Nucleotides position & Name & $5^{\prime} 10$-mer tag & $5^{\prime}$-sequence-3 & Direction \\
\hline From -1780 to -1758 & P-1780 & ACGTTGGATG & GTCCTCCTGTCCTCAGTGGAT & Forward \\
From -1584 to -1559 & P-1584_WT & ACGTTGGATG & CAGCCTGGACAACTTGGAAGAAGCC & Forward \\
From -1584 to -1559 & P-1584_MUT & ACGTTGGATG & CAGCCTGGACAACTTGGAAGAAGCG & Forward \\
From 4706 to 4728 & 2D6-R $[14]$ & ACGTTGGATG & ACTGAGCCCTGGGAGGTAGGTA & Reverse \\
\hline
\end{tabular}

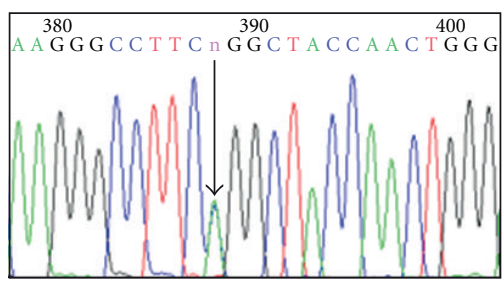

(a)

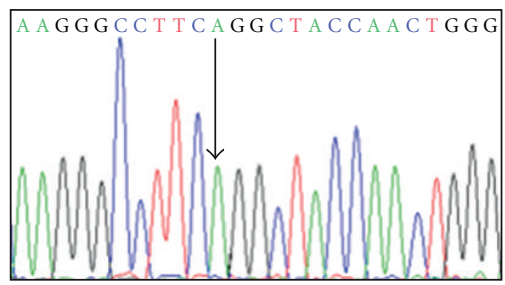

(d)

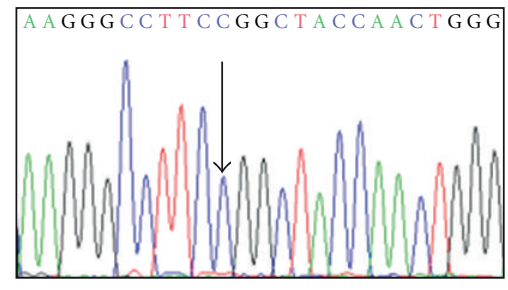

(g)

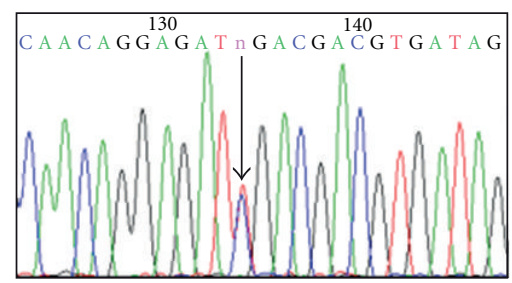

(b)

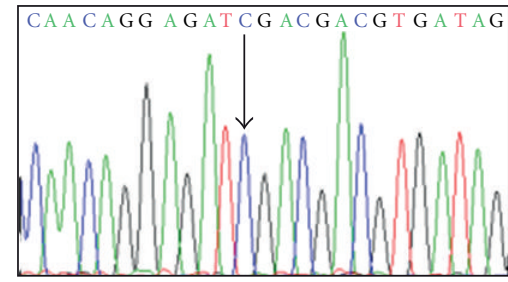

(e)

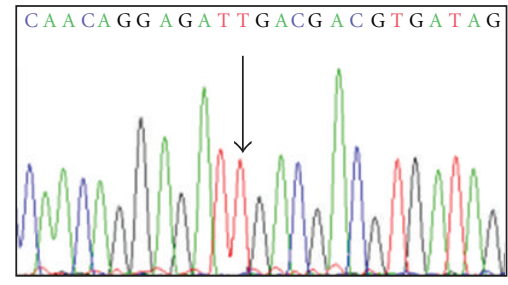

(h)

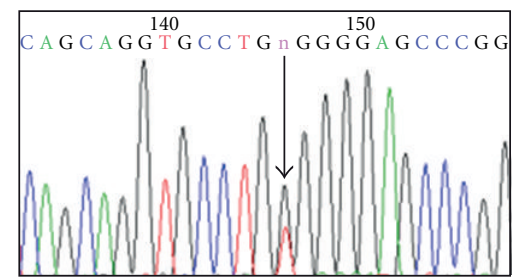

(c)

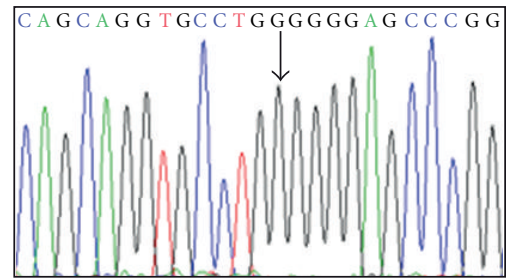

(f)

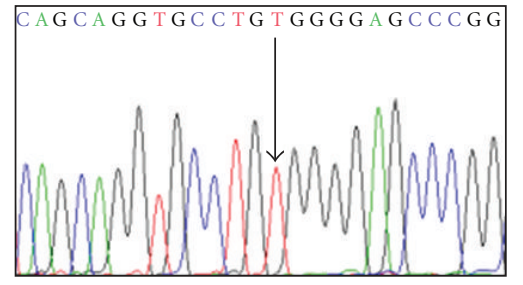

(i)

Figure 1: Electropherograms detecting the presence of three novel SNPs. (a) -948C/A; (b) 3176C/T; (c) 3948T/G. The three samples presenting novel SNPs in heterozygous status were submitted to CYP2D6 Single Allele Analysis to infer the correct phase.(d) -948A; (g) -948C; (e) 3176C; (h) 3176T; (f) 3948G; (i) 3948T. -948C >A and 3176C > T SNPs, found in two samples, were associated in the same haplotype that could be considered as a hybrid between CYP2D6 * $2 M$ and * 41 alleles ("Sardinian haplotype 2," SH2). 3948T>G SNP, found in one sample, was associated to a modification of CYP2D6 * $2 M$ allele ("Sardinian haplotype 4", SH4).

this by finding specific values for mean and variance that produce the distribution most likely to have produced the observed results. In this case, we applied the information included in the Human CYP Allele Nomenclature Committee [5] web-database to the program. We implemented a partialmatch strategy to assign the most probable haplotype using a typical set of polymorphisms that defines each allelic variant. The best assignment of the most probable haplotype to each sample assumes the presence of Hardy-Weinberg equilibrium.

2.6. CYP2D6 Single Allele Analysis. To verify the reliability of the MLE/EM algorithm and to verify the presence of novel SNPs haplotype associations in samples presenting heterozygous status for $-1584 \mathrm{G}>\mathrm{C}$ SNP, it was possible to modify the Long Range PCR protocol and apply it to new sequencing analysis. We modified the primer $-1584 \mathrm{G}>\mathrm{C}$ (Table 3 ) and added to the primer a $3^{\prime}$-dNTP complementary to the wild-type (WT) nucleotide or to SNP (MUT) to create an amplification allele-specific. For each sample a double Long PCR reaction was carried out using P-1584_WT and P-1584_MUT (Table 2) as forward primers. The reverse primer was 2D6-R [14] for both PCR reactions. A 5 ' 10-mer $\operatorname{tag}\left(5^{\prime}\right.$-ACGTTGGATG- $\left.{ }^{\prime}\right)$ was added to both PCR primers, creating a $6.379 \mathrm{~Kb}$ amplicon. In this way, we were able to directly determine the phase. PCR reactions were performed 


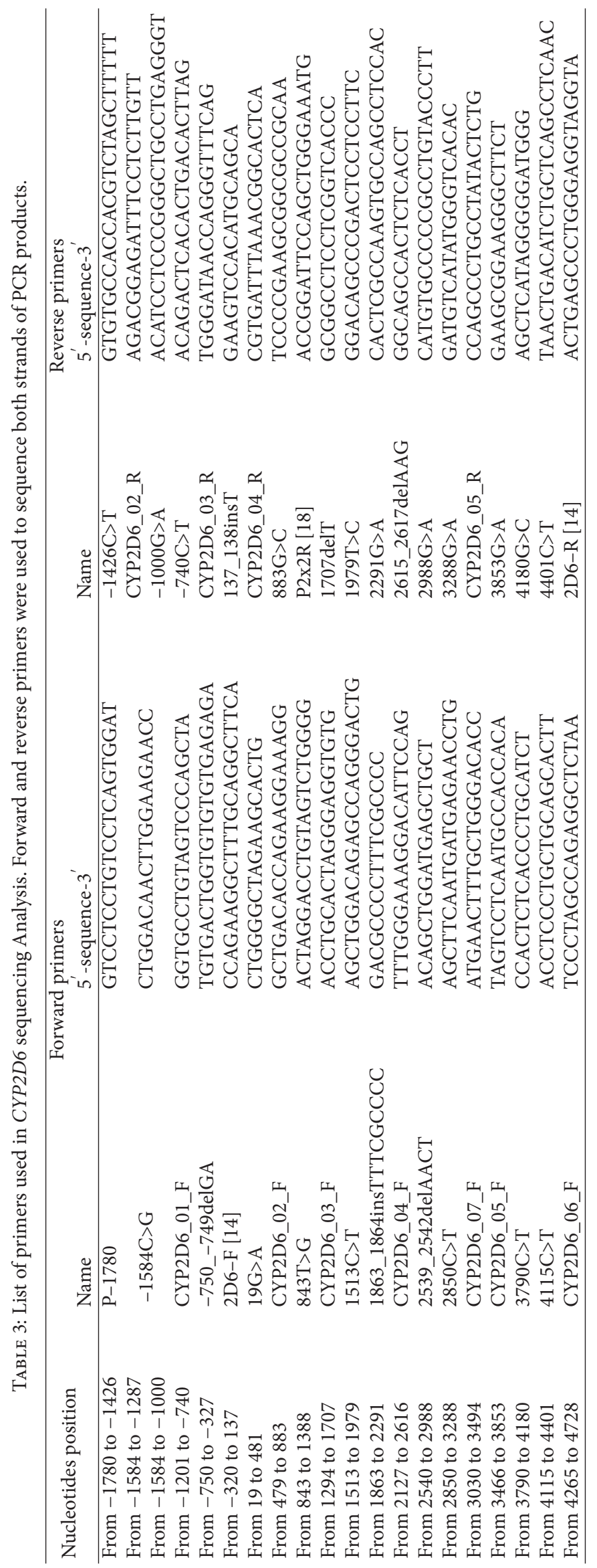




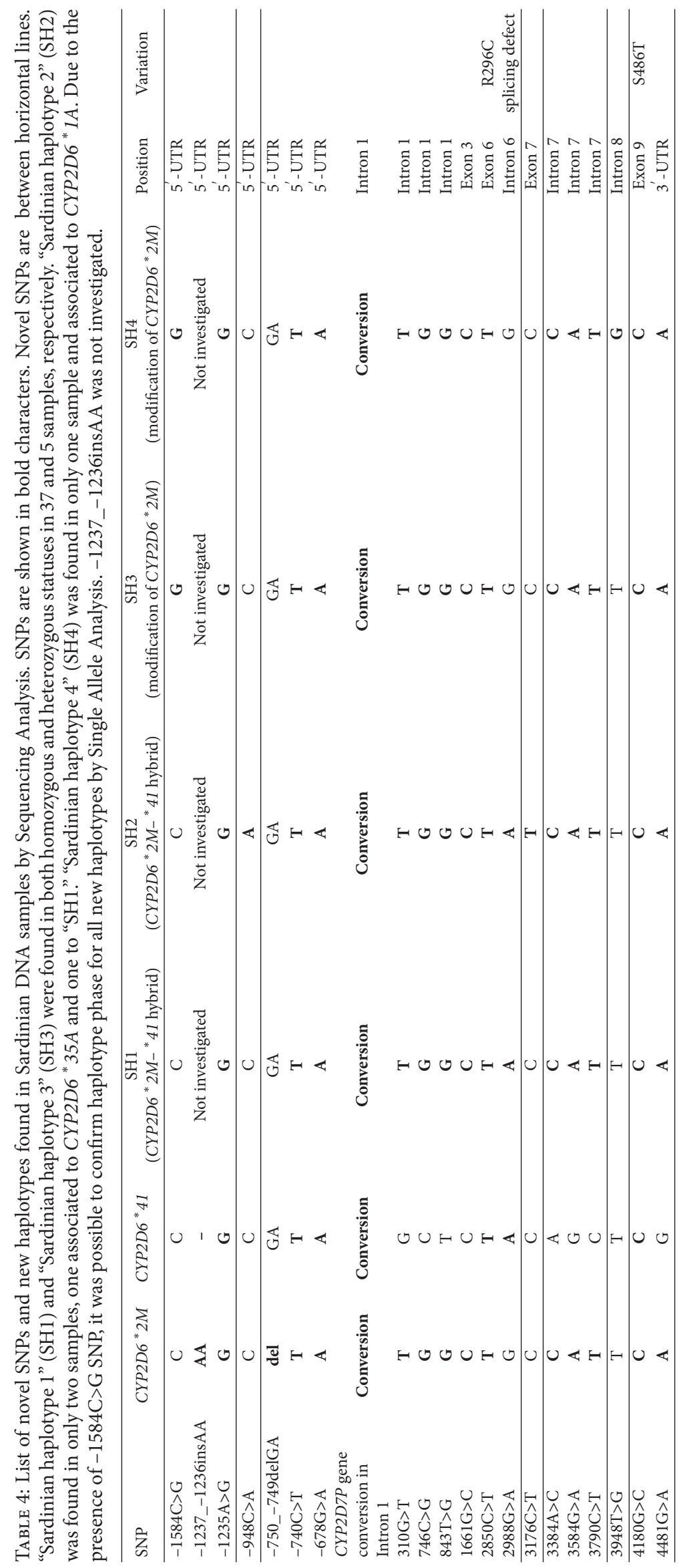


TABLE 5: CYP2D6 allele frequencies in 250 healthy Sardinian people.

\begin{tabular}{|c|c|c|c|}
\hline Variant allele & $\begin{array}{l}\text { Number of } \\
\text { chromosomes }\end{array}$ & $\begin{array}{l}\text { Frequency } \\
(\%)\end{array}$ & $\begin{array}{c}\text { Correlated enzymatic } \\
\text { activity [5] }\end{array}$ \\
\hline${ }^{*} 1 \mathrm{~A}$ & 148 & 29.6 & EM \\
\hline${ }^{*} 1 \mathrm{~B}$ & 5 & 1.0 & EM \\
\hline${ }^{*} 1 \mathrm{D}$ & 4 & 0.8 & EM \\
\hline${ }^{*} 2 \mathrm{~A}$ & 75 & 15.0 & EM \\
\hline${ }^{*} 2 \mathrm{~L}$ & 11 & 2.2 & EM \\
\hline${ }^{*} 2 \mathrm{M}$ & 8 & 1.6 & EM \\
\hline SH3 & 7 & 1.4 & Not known \\
\hline SH4 & 1 & 0.2 & Not known \\
\hline${ }^{*} 3 \mathrm{~B}$ & 11 & 2.2 & PM \\
\hline${ }^{*} 4 \mathrm{~A}$ & 84 & 16.8 & PM \\
\hline${ }^{*} 5$ & 5 & 1.0 & PM \\
\hline${ }^{*} 6 \mathrm{~A}$ & 1 & 0.2 & $\mathbf{P M}$ \\
\hline${ }^{*} 9$ & 1 & 0.2 & IM \\
\hline${ }^{*} 10 \mathrm{~B}$ & 27 & 5.4 & IM \\
\hline${ }^{*} 15$ & 3 & 0.6 & $\mathbf{P M}$ \\
\hline${ }^{*} 20$ & 1 & 0.2 & $\mathbf{P M}$ \\
\hline${ }^{*} 28$ & 4 & 0.8 & Not known \\
\hline${ }^{*} 35 \mathrm{~A}$ & 5 & 1.0 & EM \\
\hline${ }^{*} 41$ & 46 & 9.2 & IM \\
\hline SH1 & 41 & 8.2 & Not known \\
\hline $\mathrm{SH} 2$ & 2 & 0.4 & Not known \\
\hline${ }^{*} 1 \times \mathrm{N}$ & 4 & 0.8 & UM \\
\hline${ }^{*} 2 \times \mathrm{N}$ & 6 & 1.2 & UM \\
\hline
\end{tabular}

Total chromosomes number $=500$. SH1: Sardinian haplotype 1; SH2: Sardinian haplotype 2; SH3: Sardinian haplotype 3; SH4: Sardinian haplotype 4.

in a final volume of $50 \mu \mathrm{L}$ using $100 \mathrm{ng}$ genomic DNA, $400 \mu \mathrm{M}$ of each PCR Primer (Metabion), 1 U QIAGEN LongRange PCR Enzyme, 1X QIAGEN LongRange PCR Buffer (containing $\mathrm{MgCl}_{2} 25 \mathrm{mM}$ ) and $800 \mu \mathrm{M}$ Invitrogen dNTP Set PCR Grade. The PCR conditions were as follows: initial denaturation at $93^{\circ} \mathrm{C}$ for $3 \mathrm{~min} ; 12$ cycles at $93^{\circ} \mathrm{C}$ for $30 \mathrm{~s}, 67^{\circ} \mathrm{C}$ for $30 \mathrm{~s}, 68^{\circ} \mathrm{C}$ for $3 \mathrm{~min} ; 28$ cycles at $93^{\circ} \mathrm{C}$ for 30 $\mathrm{s}, 65^{\circ} \mathrm{C}$ for $30 \mathrm{~s}, 68^{\circ} \mathrm{C}$ for $6 \mathrm{~min}$. All sequencing forward and reverse reactions using the primers shown in Table 3 were carried out as indicated in "CYP2D6 Sequencing Analysis". $\mathrm{P}-1780$ and $-1426 \mathrm{C}>\mathrm{T}$ primers were not inserted in this single allele sequencing analysis.

\section{Results and Discussion}

A sample of 250 unrelated healthy Sardinian individuals was analyzed and their haplotype phases were defined. A CYP2D6 sequencing method was developed using a Long PCR strategy coupled with direct genomic sequencing analysis in order to avoid false genotyping, resulting from non-specific co-amplification of the highly homologous CYP2D7P and CYP2D8P pseudogenes. Analyses were performed by forward and reverse direct genomic DNA sequencing using ExoSAPIT and BigDye Terminator v3.1 protocols. The CYP2D6
Applied Biosystems CNV Assay was used to detect the presence of duplications or multiplications in all sequenced samples. The presence of the CYP2D6 deletion (CYP2D6 * 5 allele) was evaluated using the CYP2D6 Applied Biosystems CNV Assay, as it could not be detected by sequencing analysis. We have used the MLE based on the EM algorithm $[21,22]$ to infer the corresponding allele variants from the samples' genotypes. For some samples, it was not possible to infer any of the haplotypes indicated in the Human CYP Allele Nomenclature Committee website [5], due to the presence of new SNPs associations not described in the website. In fact, we found, in both the homozygous and heterozygous statuses, the presence of new haplotypes that could be identified as hybrids between CYP2D6 *2 $M$ and * 41 alleles ("Sardinian haplotype 1," SH1) and modification of the CYP2D6 * $2 M$ allele ("Sardinian haplotype 3", SH3) (Table 4). Moreover, we found the presence of three novel SNPs (Table 4, Figure 1). In two samples presenting SH1, sequencing analysis revealed the presence of two novel SNPs in heterozygous status ("Sardinian haplotype 2", SH2),$948 \mathrm{C}>\mathrm{A}$ found in the $5^{\prime}-\mathrm{UTR}$, and silent $3176 \mathrm{C}>\mathrm{T}$ found in Exon 7. Again, in one sample presenting $\mathrm{SH} 3$, we found the presence of one novel SNP ("Sardinian haplotype 4", $\mathrm{SH} 4), 3948 \mathrm{~T}>\mathrm{G}$ found in Intron 8. To verify the reliability of the MLE/EM algorithm, the presence of these new haplotypes and novel SNPs, and to infer the correct phase, we decided to apply a new sequencing analysis. In samples presenting a heterozygous status for $-1584 \mathrm{G}>\mathrm{C}$ SNP, it was possible to modify the Long Range PCR protocol and apply it to new sequencing analysis and create an amplification allele-specific. Sequencing analysis using forward and reverse strands of genomic DNA confirmed the presence of new haplotypes. For novel SNPs, it was possible to infer the correct phase (Table 4, Figure 1). For known haplotypes, CYP2D6 Single Allele Analysis results confirmed statistical results obtained with the MLE/EM algorithm.

Allele frequencies, detected from the 250 Sardinian individuals (Table 5), were compared with frequencies previously reported for Caucasians [11, 12, 18, 23-26] and reported in Table 6. Particularly, differences were found in CYP2D6 *2 and * 41 alleles. Readers have to consider that frequencies of these two alleles can be compared only with Raimundoet al. [23] and Sistonen et al. [11] published after the key SNP for CYP2D6 * 41 at position $2988 \mathrm{G}>\mathrm{A}$ was described. The CYP2D6 $* 2$ frequency was similar to the results of Raimundo et al. (17.5\%) [23], but in disagreement with previous study in Sardinians (35.7\%) [11]. This difference was probably due to the limited number of subjects analyzed in [11]. Particularly, We found the presence of CYP2D6 ${ }^{*} 2 A,{ }^{*} 2 L$, and ${ }^{*} 2 M$ suballeles only, where CYP2D6 ${ }^{*} 2 L(2.2 \%)$ and * $2 M(1.6 \%)$ were previously described in a South African population [27, 28]. Moreover, we detected the presence of two new haplotypes, SH3 in $1.6 \%$ of the subjects, and SH4, presenting novel SNP $3948 \mathrm{~T}>\mathrm{G}$, in $0.2 \%$ of the subjects (Table 4). We considered these haplotypes as variants of the CYP2D6 * $2 M$ suballele. On the contrary, CYP2D6 * 41 frequency was significantly higher than those previously described $(17.8 \%$ v/s 3.6-8.4\%) $[11,23]$. We found the presence of two new 


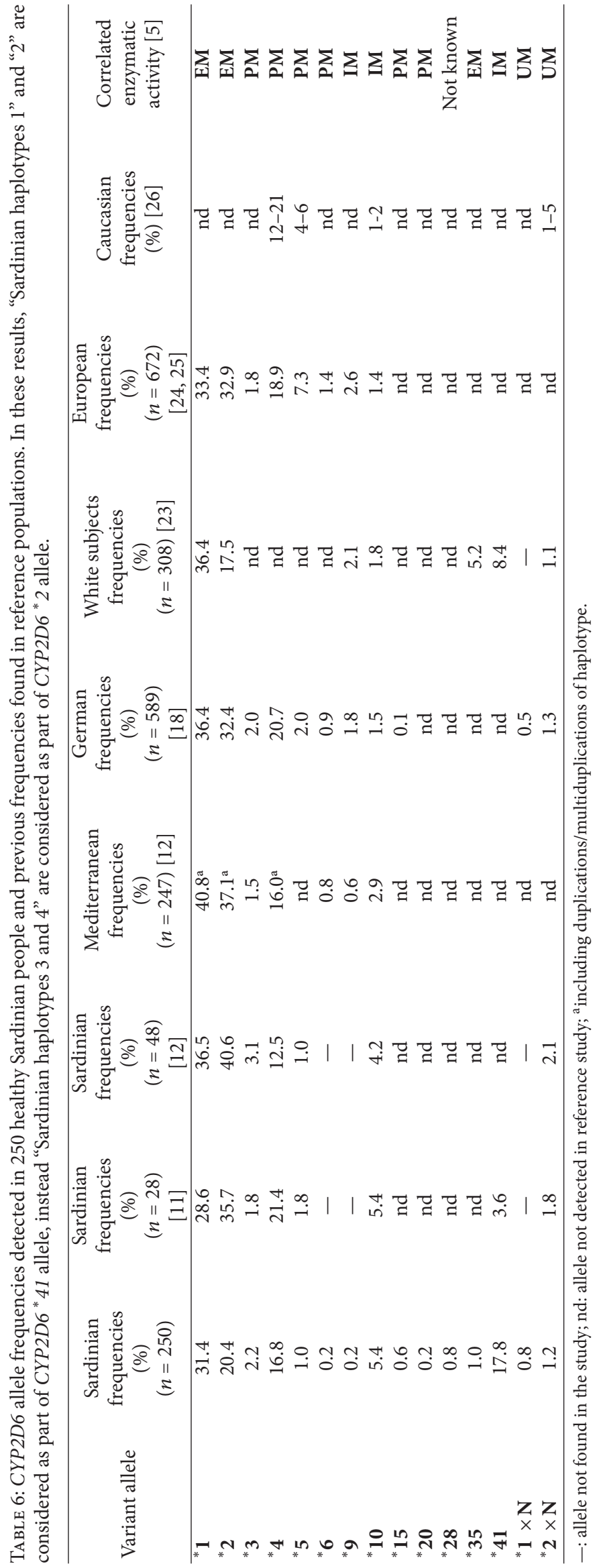


TABLE 7: CYP2D6 genotype frequencies in 250 healthy Sardinian people. In these results, "Sardinian haplotypes 1 and 2" are considered as part of CYP2D6 * 41 allele, instead "Sardinian haplotypes 3 and 4 " are considered as part of CYP2D6 ${ }^{*} 2$ allele.

\begin{tabular}{|c|c|c|c|}
\hline Genotype & $\begin{array}{c}\text { Observed } \\
\text { frequency } \\
(\%)\end{array}$ & $\begin{array}{c}\text { Predicted } \\
\text { frequency } \\
(\%)\end{array}$ & $\begin{array}{l}\text { Predicted } \\
\text { enzymatic } \\
\text { activity [5] }\end{array}$ \\
\hline${ }^{*} 1 /{ }^{*} 1$ & 9.6 & 9.9 & EM \\
\hline${ }^{*} 1 /{ }^{*} 2$ & 13.2 & 12.9 & EM \\
\hline${ }^{*} 1 /{ }^{*} 3$ & 1.6 & 1.7 & IM \\
\hline${ }^{*} 1 /{ }^{*} 4$ & 10.0 & 10.7 & IM \\
\hline${ }^{*} 1 /{ }^{*} 5$ & 0.8 & 0.6 & IM \\
\hline${ }^{*} 1 /{ }^{*} 6$ & 0.4 & 0.2 & IM \\
\hline${ }^{*} 1 /{ }^{*} 9$ & 0.4 & 0.2 & IM \\
\hline${ }^{*} 1 /{ }^{*} 10$ & 3.2 & 3.5 & IM \\
\hline${ }^{*} 1 /{ }^{*} 15$ & 0.4 & 0.5 & IM \\
\hline${ }^{*} 1 /{ }^{*} 20$ & 0.4 & 0.2 & IM \\
\hline${ }^{*} 1 /{ }^{*} 28$ & 0.4 & 0.5 & EM/IMa \\
\hline${ }^{*} 1 /{ }^{*} 35$ & 0.8 & 0.6 & EM \\
\hline${ }^{*} 1 /^{*} 41$ & 10.4 & 10.9 & IM \\
\hline${ }^{*} 1 /^{*} 1 \times \mathrm{N}$ & 0.8 & 0.6 & UM \\
\hline${ }^{*} 1 / /^{*} 2 \times \mathrm{N}$ & 0.8 & 0.6 & UM \\
\hline${ }^{*} 2 /{ }^{*} 2$ & 4.0 & 4.3 & EM \\
\hline${ }^{*} 2 /{ }^{*} 3$ & 0.8 & 1.1 & IM \\
\hline${ }^{*} 2 /{ }^{*} 4$ & 6.8 & 6.9 & IM \\
\hline${ }^{*} 2 /{ }^{*} 5$ & 0.4 & 0.5 & IM \\
\hline${ }^{*} 2 /{ }^{*} 10$ & 2.4 & 2.2 & IM \\
\hline${ }^{*} 2 /{ }^{*} 28$ & 0.4 & 0.5 & $\mathbf{E M} / \mathbf{I M}^{\mathrm{a}}$ \\
\hline${ }^{*} 2 /{ }^{*} 35$ & 0.4 & 0.5 & EM \\
\hline${ }^{*} 2 /^{*} 41$ & 7.6 & 7.1 & IM \\
\hline${ }^{*} 2 /^{*} 1 \times \mathrm{N}$ & 0.4 & 0.5 & UM \\
\hline${ }^{*} 2 /{ }^{*} 2 \times \mathrm{N}$ & 0.4 & 0.5 & UM \\
\hline${ }^{*} 3 /{ }^{*} 4$ & 0.8 & 0.9 & PM \\
\hline${ }^{*} 3 /{ }^{*} 10$ & 0.4 & 0.3 & IM \\
\hline${ }^{*} 3 /^{*} 41$ & 0.8 & 0.3 & IM \\
\hline${ }^{*} 4 /{ }^{*} 4$ & 2.8 & 2.9 & PM \\
\hline${ }^{*} 4 /^{*} 5$ & 0.4 & 0.3 & PM \\
\hline${ }^{*} 4 /^{*} 10$ & 2.0 & 1.8 & IM \\
\hline${ }^{*} 4 /{ }^{*} 15$ & 0.4 & 0.3 & $\mathbf{P M}$ \\
\hline${ }^{*} 4 /{ }^{*} 28$ & 0.4 & 0.3 & $\mathbf{I M} / \mathbf{P M}^{\mathrm{a}}$ \\
\hline${ }^{*} 4 /^{*} 35$ & 0.4 & 0.3 & IM \\
\hline${ }^{*} 4 /{ }^{*} 41$ & 6.0 & 5.8 & IM \\
\hline${ }^{*} 4 /{ }^{*} 1 \times N$ & 0.4 & 0.3 & EM \\
\hline${ }^{*} 4 /{ }^{*} 2 \times \mathrm{N}$ & 0.4 & 0.3 & EM \\
\hline${ }^{*} 5 /{ }^{*} 41$ & 0.4 & 0.3 & IM \\
\hline${ }^{*} 10 /{ }^{*} 10$ & 0.4 & 0.3 & IM \\
\hline${ }^{*} 10 /{ }^{*} 41$ & 2.0 & 1.9 & IM \\
\hline${ }^{*} 15 /{ }^{*} 41$ & 0.4 & 0.2 & IM \\
\hline${ }^{*} 28 /^{*} 41$ & 0.4 & 0.3 & $\mathbf{I M} / \mathbf{P M}^{\mathrm{a}}$ \\
\hline${ }^{*} 35 /{ }^{*} 41$ & 0.4 & 0.3 & IM \\
\hline${ }^{*} 41 /{ }^{*} 41$ & 3.2 & 3.0 & IM \\
\hline
\end{tabular}

TABLE 7: Continued.

\begin{tabular}{lccc}
\hline Genotype & $\begin{array}{c}\text { Observed } \\
\text { frequency } \\
(\%)\end{array}$ & $\begin{array}{c}\text { Predicted } \\
\text { frequency } \\
(\%)\end{array}$ & $\begin{array}{c}\text { Predicted } \\
\text { enzymatic } \\
\text { activity [5] }\end{array}$ \\
${ }^{*} \mathbf{4 1} /{ }^{*} \mathbf{1} \times \mathbf{N}$ & 0.4 & 0.3 & $\mathbf{E M}$ \\
${ }^{*} \mathbf{4 1} /{ }^{*} \mathbf{2} \times \mathbf{N}$ & 0.4 & 0.3 & $\mathbf{E M}$
\end{tabular}

Other $\quad-\quad 1.6$

$X^{2}$ test $P$ value $=0.091098$

${ }^{a}$ CYP2D6 ${ }^{*} 28$ enzymatic activity is not still described [5].

haplotypes, $\mathrm{SH} 1$ in $8.2 \%$ of the subjects and $\mathrm{SH} 2$, presenting novel SNPs-948C $>\mathrm{A}$ and $3176 \mathrm{C}>\mathrm{T}$, in $0.4 \%$ of the subjects (Table 4). We considered these haplotypes to be hybrids between $C Y P 2 D 6^{*} 2 M$ and ${ }^{*} 41$ alleles, but included them in the CYP2D6 ${ }^{*} 41$ frequency analysis due to the presence of the key SNP 2988G $>$ A, which causes a splicing defect. As for other alleles:

(i) $C Y P 2 D 6^{*} 1, * 3$ and $* 4$ frequencies are similar to reference studies; only subvariant $C Y P 2 D 6{ }^{*} 1 A,{ }^{*} 1 B$, * $1 D^{*} 3 B$ and $* 4 A$ were found.

(ii) CYP2D6 $* 6, * 9$, and $* 35$ frequencies are lower than previously described. Only sub-variant CYP2D6 * $6 \mathrm{~A}$ was found. CYP2D6 * 9 frequency is similar to that found by Fuselli et al. (0.6\%) [12], even though this study did not find CYP2D6 * 9 in Sardinians.

(iii) For CYP2D6 $* 10$ and * 15 , significant high frequencies were detected as compared to Caucasians, but CYP2D6 * 10 was in agreement with previous studies of Sardinians $[11,12]$. Only sub-variant CYP2D6 * $10 B$ was found.

(iv) CYP2D6 $* 20$ and $* 28$ alleles were not detected in reference studies, but found in Sardinians with $0.2 \%$ and $0.8 \%$ frequencies, respectively.

Deletions and duplications/multiplications were analyzed using the Applied Biosystems CNV Assay. CYP2D6 * 5, the entire gene deletion, had a significantly lower frequency as compared to the Caucasian population (1\% v/s 4-7\%), but was in agreement with previous studies in Sardinians $(1.0-1.8 \%)[11,12]$. CYP2D6 ${ }^{*} 1 x N$, duplication of the CYP2D6 * 1 allele, was found with a frequency of $0.8 \%$, in agreement only with Sachse et al. (0.5\%) [18], but not with other reference works. CYP2D ${ }^{*} 2 x N$, duplication of the CYP2D6 *2 allele, has a frequency similar to those previously described $(1.2 \% \mathrm{v} / \mathrm{s} 1-5 \%)$. No other kinds of allele duplications were found.

Sardinian genotype frequencies for the CYP2D6 gene were not deviated from expectations based on HardyWeinberg equilibrium at a significance level of $0.05\left(\chi^{2}\right.$ test $P$-value $=0.091098)$ (Table 7$)$. Predicted enzymatic activity of the 250 Sardinian individuals was different from that found in other studies (Table 8) [18, 23, 29]. EM and PM frequencies in the Sardinian subjects were lower than those previously described (29.6 v/s $37.3-56.7 \%$ and $4.4 \%$ v/s $7.2-15.9 \%$, resp.). On the contrary, IM frequencies were higher than found in other studies (62.0\% v/s 27.4-36.2). UM 
TABLE 8: CYP2D6 predicted enzymatic activity frequencies in 250 healthy Sardinian people and previous frequencies found in reference Populations. In these results, "Sardinian haplotypes 1 and 2" are considered predictive of PM phenotype as CYP2D6 * 41 allele, and "Sardinian haplotypes 3 and 4" are considered predictive of EM phenotype as CYP2D6 ${ }^{*} 2$ allele. Unkown frequency is relative to association with CYP2D6 ${ }^{*} 28$ allele.

\begin{tabular}{|c|c|c|c|c|}
\hline Predicted enzymatic activity & $\begin{array}{c}\text { Sardinian frequencies } \\
(\%) \\
(n=250)\end{array}$ & $\begin{array}{c}\text { German frequencies } \\
(\%) \\
(n=589)[18]\end{array}$ & $\begin{array}{l}\text { White subjects frequencies } \\
\qquad \begin{array}{l}(\%) \\
(n=308)[23]\end{array}\end{array}$ & $\begin{array}{c}\text { Caucasian frequencies } \\
(\%) \\
(n=44)[29]\end{array}$ \\
\hline EM & 29.6 & 53.9 & 37.3 & 56.7 \\
\hline IM & 62.0 & 36.3 & 45.5 & 27.4 \\
\hline PM & 4.4 & 7.2 & 15.9 & 15.9 \\
\hline UM & 2.4 & 2.6 & 1.3 & - \\
\hline Unknown & 1.6 & - & - & - \\
\hline
\end{tabular}

frequencies were similar in Sardinians and Caucasians $(2.4 \%$ v/s $1.3-2.6 \%)$. Finally, for $1.6 \%$ of the Sardinian subjects presenting the CYP2D6 ${ }^{*} 28$ allele in the heterozygous status, we did not infer the predicted enzymatic activity.

\section{Conclusions}

Differences in drug responses could be due to genetic factors. Knowledge of individual genetic profiling is clinically important and provides benefits for future medical care by predicting the drug response or developing DNA based tests. Substantial interindividual variability in response to specific therapies might be caused by the presence of polymorphisms in genes encoding components of drug metabolism pathways, such as the CYP450 family genes. The CYP2D6 isoenzyme is involved in the metabolism of drugs such as antipsychotics, antidepressants, $\beta$ blockers, and antiarrhythmics. Polymorphisms in this gene have been thoroughly investigated, including their associations with the incidence of adverse reactions.

In this study, we have developed a primary CYP2D6 PCR strategy based on the amplification of the entire gene coupled to direct genomic DNA sequencing analysis. Moreover, by modifying Long PCR Forward primer, we have implemented a rapid strategy to infer the phase by direct sequencing strategies.

This way, we have established the frequencies of most of the CYP2D6 Caucasian alleles in 250 Sardinian samples and found that there are some important differences to those reported in Caucasians. In our population, we found the presence of suballeles, CYP2D6 ${ }^{*} 2 L$ and ${ }^{*} 2 M$, previously found in a South African population $[27,28]$ with significant frequencies (2.2\% and $1.6 \%$ resp.) and, moreover, the presence of one novel SNP, 3948T $>$ G, and two new haplotypes, $\mathrm{SH} 3$ and $\mathrm{SH} 4$, that we categorized as variants of CYP2D6 *2 M. Furthermore, we found two novel SNPs, $-948 \mathrm{C}>\mathrm{A}$, and $3176 \mathrm{C}>\mathrm{T}$, and two new haplotypes, $\mathrm{SH} 1$ and $\mathrm{SH} 2$, that we categorized as a CYP2D6 ${ }^{*} 2 M-{ }^{*} 41$ hybrid. Due to the presence of key SNP 2988G $>$ A we classified SH1 and SH2 as sub-variants of CYP2D6 ${ }^{*} 41$ in the frequency analysis. Newly discovred SNPs were deposed on NCBI Single Nucleotide Polymorphism dbSNP [30-32] and novel sequence haplotype were deposed on NCBI GenBank [33-36]. Finally, there was a significant increase of genotypes correlated to predicted
IM and PM phenotypes, a total of $66.4 \%$ of subjects v/s $43 \%$ from reference studies $[18,29]$. The differences found between our study and previous Sardinian analyses were probably due to the limited number of SNPs and subjects analyzed by Sistonen et al. [11] and Fuselli et al. [12]. These results should be considered for future medical care when a subject is Sardinian or of direct Sardinian descendent, particularly to avoid adverse drug reactions due to the great frequency of PM and IM subjects.

\section{Conflict of Interests}

The authors declare that there is no conflict of interests.

\section{Acknowledgments}

The authors gratefully acknowledge Professor Francesco Cucca, INN-CNR Cagliari Director, for gently furnishing Sardinian DNAs; Dr. Maristella Pitzalis and Dr. Francesca Deidda for technical assistance in DNA Sequencing; Dr. Luisella Saba, Dr. Elena Congeddu and Dr. Enrico Sorisio, PharmaNess Sole Director, for useful information provided. A special thanks goes to Professor Annalisa Marchi who has kindly allowed the completion of this paper in her laboratories.

\section{References}

[1] M. Eichelbaum, M. Ingelman-Sundberg, and W. E. Evans, "Pharmacogenomics and individualized drug therapy," Annual Review of Medicine, vol. 57, pp. 119-137, 2006.

[2] M. Ingelman-Sundberg, "Genetic polymorphisms of cytochrome P450 2D6 (CYP2D6): clinical consequences, evolutionary aspects and functional diversity," Pharmacogenomics Journal, vol. 5, no. 1, pp. 6-13, 2005.

[3] D. A. Flockhart, Drug Interactions: Cytochrome P450 Drug Interaction Table, Indiana University School of Medicine, 2008.

[4] B. Bondy and I. Spellmann, "Pharmacogenetics of antipsychotics: useful for the clinician?" Current Opinion in Psychiatry, vol. 20, no. 2, pp. 126-130, 2007.

[5] Human Cytochrome P450 Allele Nomenclature Committee, http://www.cypalleles.ki.se/.

[6] M. Ingelman-Sundberg, S. C. Sim, A. Gomez, and C. Rodriguez-Antona, "Influence of cytochrome $\mathrm{P} 450$ polymorphisms 
on drug therapies: pharmacogenetic, pharmacoepigenetic and clinical aspects," Pharmacology and Therapeutics, vol. 116, no. 3, pp. 496-526, 2007.

[7] M. Ingelman-Sundberg, "Pharmacogenetics of cytochrome P450 and its applications in drug therapy: the past, present and future," Trends in Pharmacological Sciences, vol. 25, no. 4, pp. 193-200, 2004.

[8] M. Falzoi, A. Mossa, E. Congeddu, L. Saba, and L. Pani, "Multiplex genotyping of CYP3A4, CYP3A5, CYP2C9 and CYP2C19 SNPs using MALDI-TOF mass spectrometry," Pharmacogenomics, vol. 11, no. 4, pp. 559-571, 2010.

[9] R. Lampis, L. Morelli, S. De Virgiliis, M. Congia, and F. Cucca, "The distribution of HLA class II haplotypes reveals that the Sardinian population is genetically differentiated from the other Caucasian populations," Tissue Antigens, vol. 56, no. 6, pp. 515-521, 2000.

[10] I. A. Eaves, T. R. Merriman, R. A. Barber et al., "The genetically isolated populations of Finland and Sardinia may not be a panacea for linkage disequilibrium mapping of common disease genes," Nature Genetics, vol. 25, no. 3, pp. 320-323, 2000.

[11] J. Sistonen, A. Sajantila, O. Lao, J. Corander, G. Barbujani, and S. Fuselli, "CYP2D6 worldwide genetic variation shows high frequency of altered activity variants and no continental structure," Pharmacogenetics and Genomics, vol. 17, no. 2, pp. 93-101, 2007.

[12] S. Fuselli, I. Dupanloup, E. Frigato et al., "Molecular diversity at the CYP2D6 locus in the Mediterranean region," European Journal of Human Genetics, vol. 12, no. 11, pp. 916-924, 2004.

[13] Homo sapiens cytochrome P4502D6 (CYP2D6) gene, CYP2D6* 1 allele, complete cds, http://www.ncbi.nlm.nih.gov/ nucleotide/45024927?.

[14] I. Johansson, E. Lundqvist, M. L. Dahl, and M. IngelmanSundberg, "PCR-based genotyping for duplicated and deleted CYP2D6 genes," Pharmacogenetics, vol. 6, no. 4, pp. 351-355, 1996.

[15] QIAGEN LongRange PCR Handbook 2008 http://www.qiagen .com/default.aspx.

[16] SEQUENOM RealSNPTM Assay Database, https://seqpws1 .sequenom.com/AssayDesignerSuite.html\#design:new=Genotyping.

[17] Primer3 v. 0.4.0, http://frodo.wi.mit.edu/primer3/.

[18] C. Sachse, J. Brockmöller, S. Bauer, and I. Roots, "Cytochrome P450 2D6 variants in a Caucasian population: allele frequencies and phenotypic consequences," American Journal of Human Genetics, vol. 60, no. 2, pp. 284-295, 1997.

[19] Human cytochrome P450 IID6 (CYP2D6) gene, complete cds, http://www.ncbi.nlm.nih.gov/nuccore/181303?.

[20] TaqMan Copy Number Assays Protocol, 2009, http://www .appliedbiosystems.com/.

[21] M. Stephens, N. J. Smith, and P. Donnelly, "A new statistical method for haplotype reconstruction from population data," American Journal of Human Genetics, vol. 68, no. 4, pp. 978-989, 2001.

[22] L. Excoffier and M. Slatkin, "Maximum-likelihood estimation of molecular haplotype frequencies in a diploid population," Molecular Biology and Evolution, vol. 12, no. 5, pp. 921-927, 1995.

[23] S. Raimundo, C. Toscano, K. Klein et al., "A novel intronic mutation, 2988G $>$ A, with high predictivity for impaired function of cytochrome P450 2D6 in white subjects," Clinical Pharmacology and Therapeutics, vol. 76, no. 2, pp. 128-138, 2004.
[24] L. D. Bradford, "CYP2D6 allele frequency in European Caucasians, Asians, Africans and their descendants," Pharmacogenomics, vol. 3, no. 2, pp. 229-243, 2002.

[25] D. Marez, M. Legrand, N. Sabbagh et al., "Polymorphism of the cytochrome P450 CYP2D6 gene in a European population: characterization of 48 mutations and 53 alleles, their frequencies and evolution," Pharmacogenetics, vol. 7, no. 3, pp. 193-202, 1997.

[26] M. Ingelman-Sundberg, "Implications of polymorphic cytochrome P450-dependent drug metabolism for drug development," Drug Metabolism and Disposition, vol. 29, no. 4, pp. 570-573, 2001.

[27] A. Gaedigk, A. Bhathena, L. Ndjountché et al., "Identification and characterization of novel sequence variations in the cytochrome P4502D6 (CYP2D6) gene in African Americans," Pharmacogenomics Journal, vol. 5, no. 3, pp. 173-182, 2005.

[28] A. Gaedigk, L. Ndjountché, J. S. Leeder et al., "Limited association of the $2988 \mathrm{G}>$ A single nucleotide polymorphism with CYP2D6* 41 in black subjects," Clinical Pharmacology and Therapeutics, vol. 77, no. 3, pp. 228-231, 2005.

[29] T. Shimada, F. Tsumura, H. Yamazaki, F. P. Guengerich, and K. Inoue, "Characterization of ( \pm )-bufuralol hydroxylation activities in liver microsomes of Japanese and Caucasian subjects genotyped for CYP2D6," Pharmacogenetics, vol. 11, no. 2, pp. 143-156, 2001.

[30] ss469415642 (2011) CYP2D6 3176C>T, http://www.ncbi.nlm .nih.gov/projects/SNP/snp_ss.cgi?ss=469415642.

[31] ss469415643 (2011) CYP2D6 3948T>G, http://www.ncbi.nlm .nih.gov/projects/SNP/snp_ss.cgi?ss=469415643.

[32] ss470263991 (2011) CYP2D6 -948C>A, http://www.ncbi.nlm .nih.gov/projects/SNP/snp_ss.cgi?ss $=470263991$.

[33] M. Falzoi, L. Pira, P. Lazzari, and L. Pani. GenBank, Homo sapiens haplotype 1 cytochrome P450 2D6 variant (CYP2D6) gene, CYP2D6 ${ }^{*} 2 M$ allele, complete cds, JN716373. 1, 2011, http://www.ncbi.nlm.nih.gov/nuccore/JN716373.

[34] M. Falzoi, L. Pira, P. Lazzari, and L. Pani, Homo sapiens haplotype 2 cytochrome P450 2D6 variant (CYP2D6) gene, CYP2D6* $2 M$ allele, complete cds. GenBank: JN716374. 1, 2011, http://www.ncbi.nlm.nih.gov/nuccore/JN716374.

[35] M. Falzoi, L. Pira, P. Lazzari, and L. Pani, Homo sapiens haplotype 3 cytochrome P450 2D6 variant (CYP2D6) gene, CYP2D6* M/CYP2D6* 41 hybrid allele, complete cds. GenBank: JN716375. 1, 2011, http://www.ncbi.nlm.nih.gov/nuccore/ JN716375.

[36] M. Falzoi, L. Pira, P. Lazzari, and L. Pani, Homo sapiens haplotype 4 cytochrome P450 2D6 variant (CYP2D6) gene, CYP2D6* 2M/CYP2D6* 41 hybrid allele, complete cds. GenBank: JN716376. 1, 2011, http://www.ncbi.nlm.nih.gov/nuccore/JN716376. 

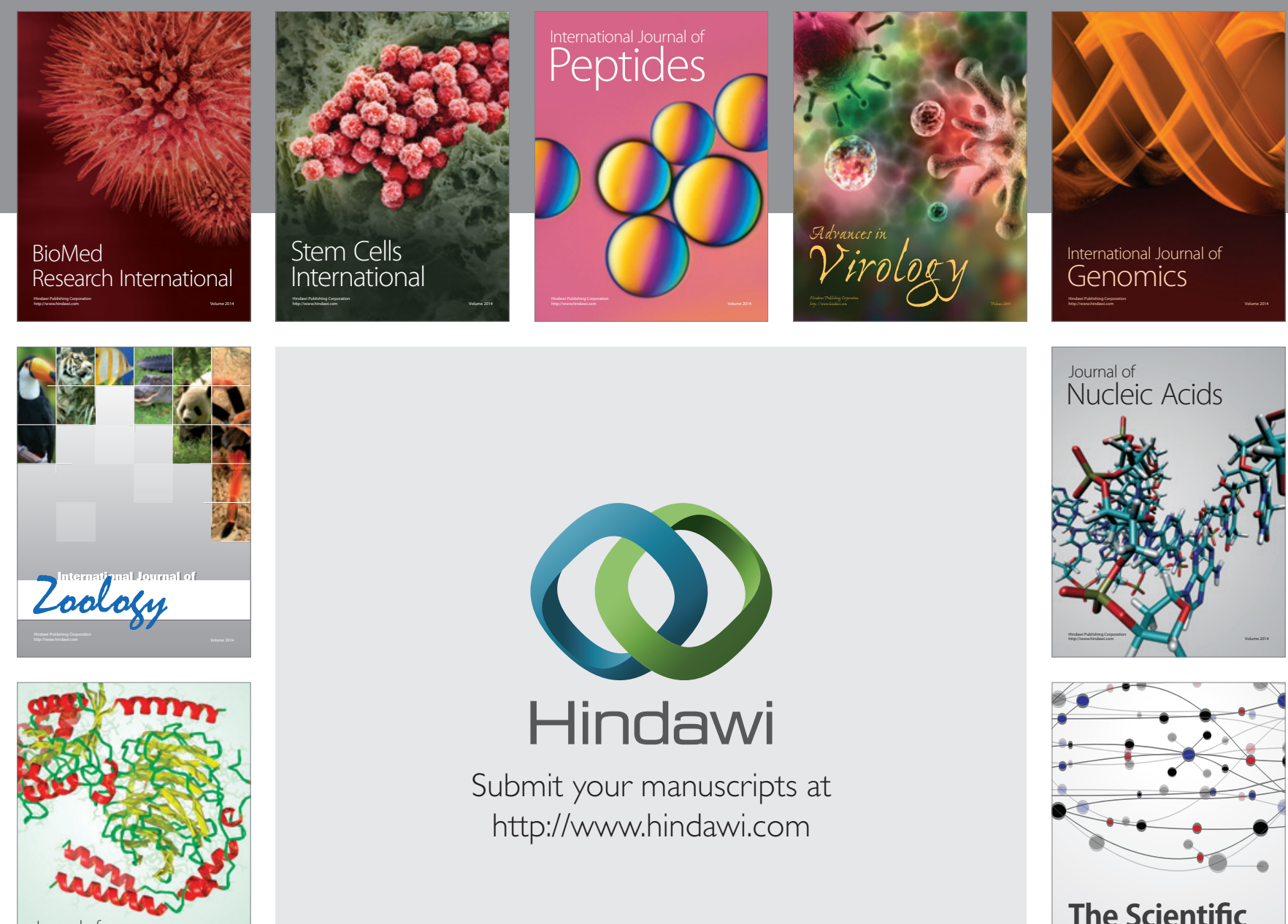

Submit your manuscripts at

http://www.hindawi.com

Journal of
Signal Transduction
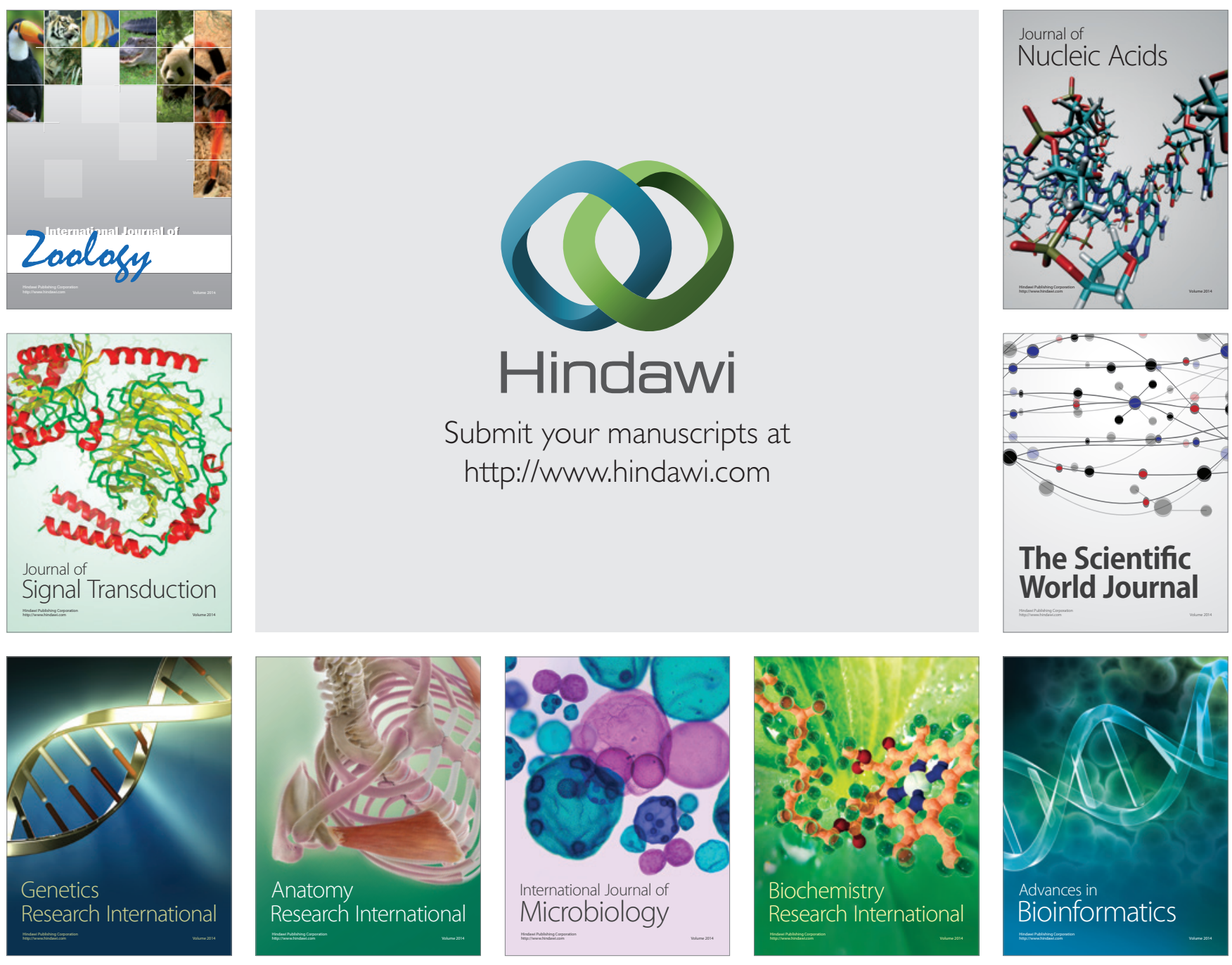

The Scientific World Journal
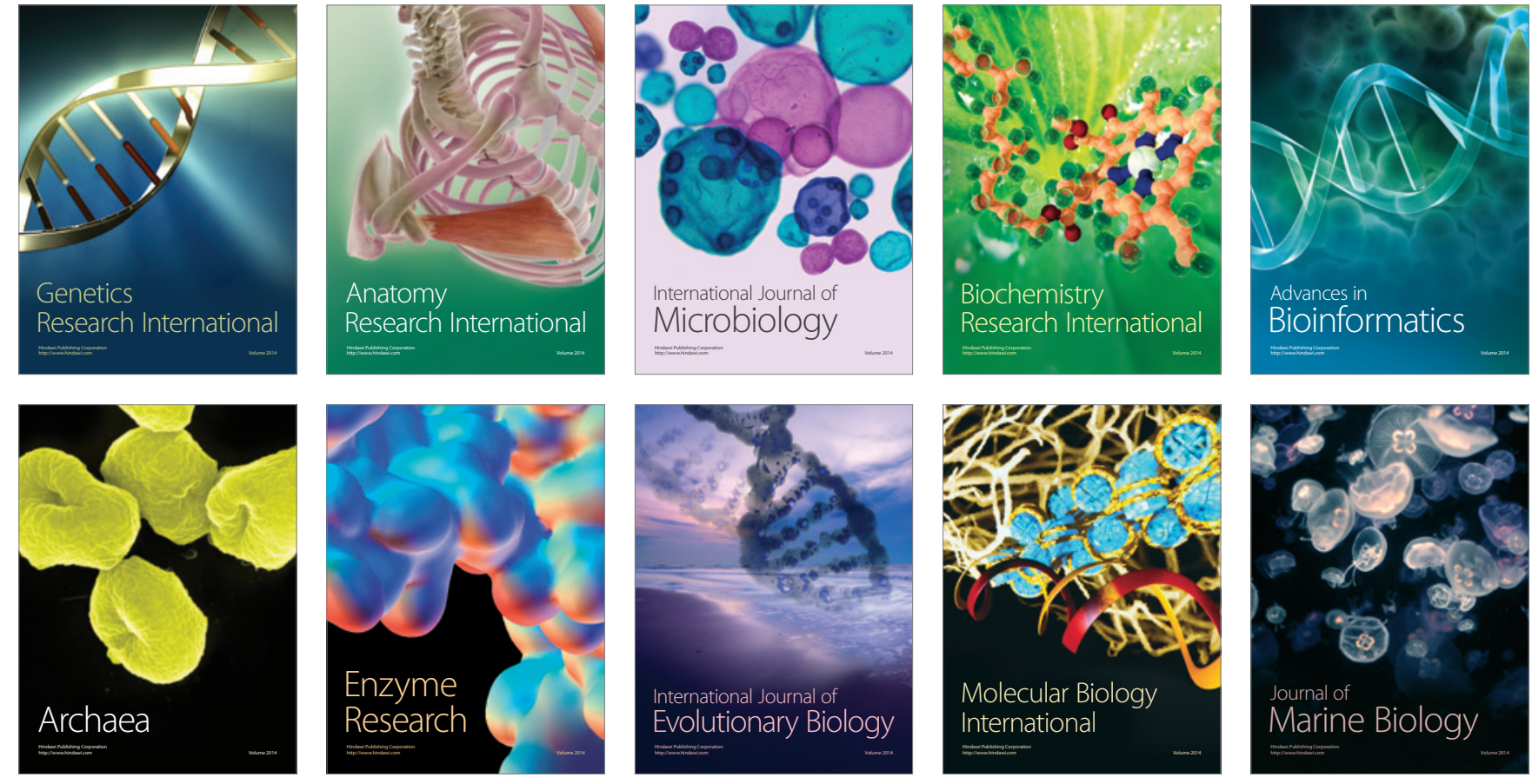